JURNAL PENDIDIKAN ISLAM IQRA' Vol. 11. Nomor 1

Fakultas Tarbiyah dan Ilmu Keguruan [FTIK]

IAIN Manado

\title{
Implementasi Pendidikan Karakter di Sekolah dan Perguruan Tinggi Melalui Pembelajaran Aktif
}

\author{
Abd. Latif Samal \\ Email :abdulatif0102@gmail.com \\ Institut Agama Islam Negeri (IAIN) Manado
}

\section{Pendahuluan}

Tujuan pendidikan yang paling mendasar, menurut Socrates, adalah membentuk peserta didik menjadi "good and smart" yang menjadi insan yang berakhlak mulia atau berbudi luhur serta cerdas, kritis dan kreatif (Djalil, 2006). Pemerintah dan bangsa Indonesia telah menyadari hal tersebut dan menjabarkannya ke dalam Undang-Undang Nomor 20 Tahun 2003 tentang Sistem Pendidikan Nasional (Sisdiknas), khususnya pasal 3 yang berbunyi "Pendidikan nasional berfungsi mengembangkan kemampuan dan membentuk watak serta peradaban bangsa yang bermanfaat dalam rangka mencerdaskan kehidupan bangsa, bertujuan untuk berkembangnya potensi peserta didik agar menjadi manusia yang beriman dan bertagwa terhadap Tuhan Yang Maha Esa, berakhlak mulia, sehat, berilmu, cakap, kreatif, mandiri, dan menjadi warga Negara yang demokratis serta bertanggungjawab".

Berdasarkan amanat undang-undang tersebut, sangatlah jelas bahwa sistem pendidikan nasional berfungsi untuk mengembangkan potensi diri peserta didik untuk memiliki kemampuan yang dilandasi oleh karakter yang kuat, yaitu memiliki keimanan, ketaqwaan, kepribadian, akhlak mulia dan kemandirian. Namun kita patut bertanya "sudahkah tujuan tersebut telah tercapai?" sudah 
JURNAL PENDIDIKAN ISLAM IQRA' Vol. 11. Nomor 1

Fakultas Tarbiyah dan Ilmu Keguruan [FTIK]

IAIN Manado

mampukah pendidikan kita menghasilkan bangsa yang berkarakter kuat dan berkemampuan tinggi?”.

Terkait dengan pernyataan tersebut, Lickona (1992) menyatakan bahwa terdapat sepuluh tanda-tanda yang mencirikan kehancuran suatu bangsa, yaitu (1) meningkatnya kekerasan di kalangan remaja, (2) penggunaan bahasa dan katakata yang memburuk, (3) pengaruh peer group yang kuat dalam tindakan kekerasan, (4) meningkatnya perilaku merusak diri, (5) semakin kabarnya pedoman moral baik dan buruk, (6) menurunnya etos kerja, (7) semakin rendahnya rasa hormat kepada orang tua dan guru, (8) rendahnya rasa tanggungjawab individu dan warga Negara, (9) membudayanya perilaku ketidakjujuran, dan (10) adanya rasa saling curiga dan kebencian di antara sesama.

Pada saat ini kesepuluh tanda tersebut tampak sudah dan sedang terjadi di Indonesia. Kita sangat mudah mencari buktinya. Di antaranya adalah membudaya praktik KKN (Korupsi, Kolusi, dan Nepotisme), membaiknya konflik (antar etnis, agama, politisi, kelompok sosial, dan sebagainya), tindakan terorisme yang semakin berani, maraknya peredaran dan konsumsi narkoba, merebaknya LGBT (Lesbian, Gay, Bisexualities, dan Transgender), meningkatnya kriminalitas, tawuran antarpelajar, dan banyak lagi. Oleh karena itu kita patut bertanya "Apakah demoralisasi yang terjadi menandakan bahwa bangsa Indonesia sedang menuju kehancuran.”

Kondisi tersebut tentu tidak dapat dilepaskan dengan strategi pendidikan selama ini kita terapkan. Merupakan kenyataan bahwa pendidikan yang kita laksanakan lebih menekankan penguasaan aspek pengetahuan (kognitif) daripada 
JURNAL PENDIDIKAN ISLAM IQRA' Vol. 11. Nomor 1

Fakultas Tarbiyah dan Ilmu Keguruan [FTIK]

IAIN Manado

aspek afektif dan psikomotorik, dan lebih menyiapkan para peserta didik melanjutkan ke jenjang perguruan tinggi. Hal tersebut dapat dibuktikan melalui bobot pembelajaran yang lebih banyak ditekankan pada pengembangan potensi akademik peserta didik yang diukur dengan kemampuan logika matematika dan abstraksi (kemampuan berbahasa, menghafal, abstraksi atau ukuran IQ). Padahal ada banyak potensi lain-lain yang perlu dikembangkan, karena berdasarkan teori Howard Gardner tentang kecerdasan majemuk, potensi akademik hanyalah sebagian saja dari potensi-potensi lainnya. Oleh karena itu, banyak materi pelajaran yang berkaitan dengan pengembangan otak kanan (seperti kesenian, keterampilan, musik, imajinasi, dan pembentukan karekater), kurang mendapatkan perhatian. Celakanya, pendekatan yang terlalu kognitif juga telah mengubah orientasi belajar para siswa menjadi semata-mata untuk meraih nilai tinggi. Hal tersebut mendorong para siswa/mahasiswa untuk mengejar nila dengan cara tidak jujur, seperti mencontek, menjiplak, mengupah pembuatan skripsi, dan sebagainya (Djalil, 2006).

Dari sisi metode pedagogik, pendidikan diharapkan melaksanakan strategi pembelajaran yang membuat para peserta didik menjadi kreatif, percaya diri, kritis dan berkarakter mulia. Strategi-strategi pembelajaran yang membuat para peserta didik menjadi kreatif, percaya diri, kritis dan berkarakter mulia. Strategi-strategi ini mensyaratkan peserta didik terlibat penuh dalam pembelajaran sehingga dapat belajar dengan "cara" mereka sendiri. Mereka aktif melaksanakan, berkolaborasi, dan bereksplorasi dalam pembelajaran, dalam hal ini pendidik lebih memfungsikan diri sebagai fasilitator pembelajaran. Namun apabila kita lihat 
JURNAL PENDIDIKAN ISLAM IQRA' Vol. 11. Nomor 1

Fakultas Tarbiyah dan Ilmu Keguruan [FTIK]

IAIN Manado

kenyataan, para guru di Indonesia lebih banyak mendominasi pembelajaran. Metode yang digunakan lebih banyak konvensional, seperti metode ceramah, tanya jawab, diskusi, dan pemberian tugas, singkatnya para guru lebih banyak melaksanakan kegiatan "teach more and learn less" sementara diharapkan adalah sebaliknya, "teach less, learn more”.

Seperti yang dikemukakan oleh Bransford (1990), masalah yang paling mendasar pendidikan adalah pembelajaran tradisional gagal menghasilkan kemampuan memecahkan masalah kehidupan karena hanya memberikan permasalahan yang disederhanakan (simplified), didekontekstualisasi (decontextualized) dan secara eksplisit tidak relevan dengan masalah yang benarbenar dihadapi siswa pada kehidupan yang sebenarnya.

Menyadari kekurangan-kekurangan dalam system pendidikan kita, berbagai inovasi pendidikan, baik secara substansial maupun metodologis, perlu dilaksanakan untuk mengurai dan mengurangi tekanan terhadap pendidikan di Indonesia. Secara metodologis, salah satu strategi yang sudah, sedang dan akan diberlakukan adalah penggunaan active learning methods yang menekankan pembelajaran aktif bagi siswa.

\section{Pembelajaran aktif}

"Active learning" atau pembelajaran aktif merupakah istilah umum mengenal penggunaan berbagai metode di kelas atau penciptaan lingkungan pembelajaran dimana siswa terlibat secara aktif dalam pembelajaran yang mereka lakukan (Sukarno, 2014). Dalam kaitannya dengan hal ini Chickering dan 
JURNAL PENDIDIKAN ISLAM IQRA' Vol. 11. Nomor 1

Fakultas Tarbiyah dan Ilmu Keguruan [FTIK]

IAIN Manado

Gamson (1987) mengemukakan bahwa pembelajaran seharusnya bukanlah sekedar olah raga tontonan, siswa tidak belajar banyak hanya dengan duduk di kelas, mendengarkan guru, mengerjakan tugas yang diberikan, dan melontarkan jawaban. Mereka harus membicarakan apa yang mereka pelajari, menuliskannya, menghubungkannya dengan pengalaman di masa lalu, dan menerapkannya pada kehidupan keseharian mereka.

Berbagai pendekatan dan metode digunakan dalam pembelajaran aktif sehingga melahirkan istilah-istilah seperti pembelajaran berpusat pada siswa (student-centered learning), pembelajaran yang diatur sendiri (self-regulated learning), pembelajaran kolaboratif (collaborative learning), pembelajaran untuk belajar (learning to learn), pembelajaran berbasis masalah (problem based learning), pembelajaran berbasis inkuiri (inquiry based learning) yang kesemuanya mengharapkan siswa terlibat secara aktif dalam pembelajaran mereka sendiri. Prince (2004) mengemukakan bahwa unsur dasar pembelajaran aktif adalah kegiatan siswa dan keterlibatan siswa dalam proses pembelajaran.

\section{Teori yang melatarbelakangi pembelajaran aktif}

Dalam pembelajaran aktif, diyakini secara mendasar bahwa para siswa harus melaksanakan keterampilan berpikir dan belajar tingkat tinggi untuk penguasaan secara efektif pengetahuan dan keterampilan baru. Salah satu teori yang mendasari pembelajaran aktif adalah taksonomi pembelajaran Bloom. Diagram I berikut ini memajangkan piramida hierarki keterampilan yang intelektual. Setiap kegiatan pembelajaran diharapkan melibatkan keterampilan 
JURNAL PENDIDIKAN ISLAM IQRA' Vol. 11. Nomor 1

Fakultas Tarbiyah dan Ilmu Keguruan [FTIK]

IAIN Manado

intelektual tingkat tinggi yang diperlukan setiap pembelajar, tidak sekedar mengetahui dan memahami, tetapi juga menerapkan, menganalisis, mengevaluasi, dan mencipta. Secara praktis, setiap kali kegiatan pembelajaran tingkat tinggi dilaksanakan, saat itu pula akan terjadi pembelajaran yang bermakna dan efektif. Tatkala para pembelajar terlibat dalam kegiatan menantang mereka untuk menggunakan keterampilan-keterampilan intelektual tingkat tinggi ini, pembelajaran mereka tidak hanya akan menjadi lebih aktif tetapi pada saat yang sama mereka juga mengembangkan keterampilan professional yang mereka butuhkan dalam studi mereka.

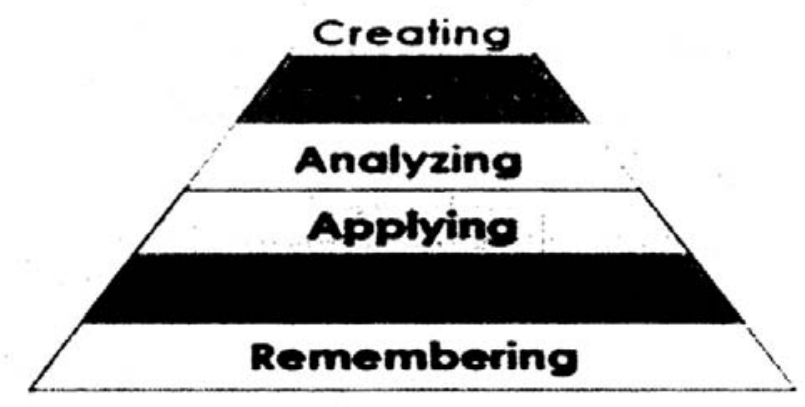

\section{Diagram 1: Bloom's New Taxonomy of Learning (Source: Overbaugh and Schultz, 2012) www.odu.edu/educ/roverbaw/Bloom/blooms_taxonomy.htm}

Pengajaran tradisional biasanya memusatkan kegiatan hanya pada tingkatan rendah, yaitu mengingat dan memahami, dengan menanamkan informasi dan membantu pembelajaran memahami materi pembelajaran. Untuk dapat menguasai keterampilan-keterampilan tingkat tinggi tersebut, stratei-strategi tinggi tersebut, strategi-strategi baru diperlukan pembelajar, yang antara lain melputi. 
JURNAL PENDIDIKAN ISLAM IQRA' Vol. 11. Nomor 1

Fakultas Tarbiyah dan Ilmu Keguruan [FTIK]

IAIN Manado

- Menerapkan pengetahuan baru, prosedur baru, atau keterampilan baru

- Menganalisis pengetahuan dan prosedur baru untuk memahami hubungan antara langkah, menganalisis aspek-apek keterampilan baru yang berbedabeda.

- Mengevaluasi informasi, prosedur, atau keterampilan baru dan

- Menciptakan sesuatu yang baru berdasarkan pengetahuan, prosedur atau keterampilan yang baru (Sukarno, 2014).

Dalam kelasnya dengan hal tersebut di atas, seorang guru atau dosen tidak hanya perlu memutuskan pengetahuan, prosedur atau keterampilan mana yang perlu dibicarakan dengan siswa atau mahasiswa, tetapi juga bahwa mereka sendiri juga harus menganalisis pengalaman belajar para siswa mereka, mengevaluasi apakah pengalaman tersebut efektif untuk mendukung pencapaian tujuan pembelajaran, dan kalau tidak sebuah strategi baru perlu dipilih. Oleh karena itu setiap rencana pembelajaran dapat berfungsi sebagai proyek penelitian tindakan kelas kecil untuk melihat apakah strategi yang dipilih telah sesuai atau belum. Dalam hal ini terdapat perubahan dari peran guru atau dosen sebagai penyedia informasi menjadi fasilitator pembelajaran yang membantu siswa atau mahasiswa menemukan sebuah informasi baru atau bahkan menciptakan informasi baru.

\section{Keragaman Metode Pembelajaran}


JURNAL PENDIDIKAN ISLAM IQRA' Vol. 11. Nomor 1

Fakultas Tarbiyah dan Ilmu Keguruan [FTIK]

IAIN Manado

Strategi seperti apa yang digunakan untuk dapat melaksanakan pembelajaran aktif? Apakah metode ceramah masih diperlukan? Pemilihan metode dalam pembelajaran aktif harus didasarkan pada yang hubungan dengan konteks pembelajaran, namun yang berikut ini memberikan opsi pilihan pembelajaran aktif, sebagaimana digambarkan pada table 1 (Paulson dan Faust, 2012).

Tabel 1 Metode Pembelajaran Aktif Untuk Pendekatan Tinggi

\begin{tabular}{|c|c|}
\hline \multicolumn{2}{|c|}{ Jenis-jenis Metode Pembelajaran Aktif } \\
\hline $\begin{array}{l}\text { Latihan individual } \\
\text { - The one minute paper } \\
\text { - The muddiest (or clearest) point } \\
\text { - Effective responses } \\
\text { - Daily Journal } \\
\text { - Reading quiz } \\
\text { - Clarification pauses } \\
\text { - Response to demonstration of order } \\
\text { teacher centered activity }\end{array}$ & $\begin{array}{l}\text { Tanya jawab (metode sokratik) } \\
\text { - Wait time } \\
\text { - Peer summary } \\
\text { - } \quad \text { The fish bowl } \\
\text { - } \quad \text { Quiz/test questions }\end{array}$ \\
\hline $\begin{array}{l}\text { Masukan langsung } \\
\text { - Finger signals } \\
\text { - Flash cards } \\
\text { - Quotations }\end{array}$ & $\begin{array}{l}\text { Motivator berpikir kritis } \\
\text { - The fre theoretic institution quiz } \\
\text { - Puzzles/paradoses }\end{array}$ \\
\hline $\begin{array}{l}\text { Pasangan } \\
\text { - Discussion } \\
\text { - Note comparison taking } \\
\text { - Evaluation of another stundent's } \\
\text { work }\end{array}$ & $\begin{array}{l}\text { Latihan pembelajaran kooperatif } \\
\text { - } \text { Cooperative groups in class } \\
\text { - } \text { Active review sessions } \\
\text { - } \text { Work at the blackboard } \\
\text { - Concept mapping } \\
\text { - Visual lists } \\
\text { - Jigsaw group project } \\
\text { - } \quad \text { Role playing }\end{array}$ \\
\hline
\end{tabular}


JURNAL PENDIDIKAN ISLAM IQRA' Vol. 11. Nomor 1

Fakultas Tarbiyah dan Ilmu Keguruan [FTIK]

IAIN Manado

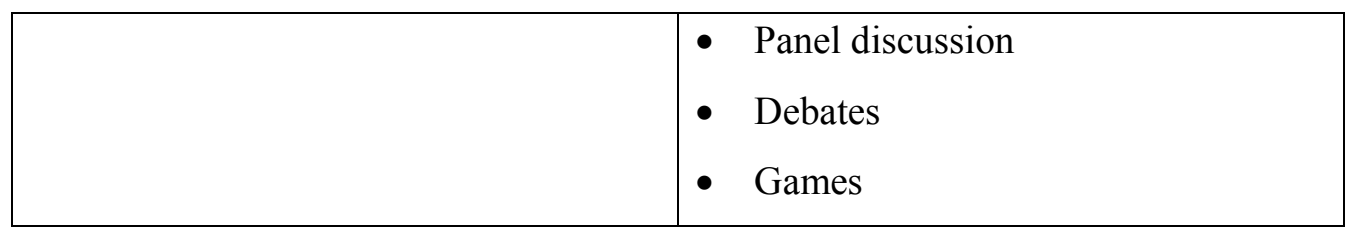

(Sumber Paulson and Faust, 2012)

Dengan kegiatan-kegiatan seperti tersebut di atas, para pendidik dapat memikirkan dan memilih peralatan pembelajaran dalam merencanakan pengajaran mereka. Banyak teknil lain yang tersedi dan browsing cepat di internet akan dengan sangat mudah memberikan pilihan lain yang mungkin lebih tepat. Para pendidik juga sangat dimungkinkan menciptakan sendiri teknik-teknik mereka sendiri.

\section{Karakter Bangsa}

Secara etimologis, kata karakter berasal dari bahasa Inggris character, yang berarti watak atau sifat. Karakter adalah nilai-nilai khas, baik watak, akhlak atau kepribadian seseorang yang terbentuk dari hasil internalisasi berbagai kebijakan yang diyakini dan dipergunakan sebagai cara pandang, berpikir, bersikap, berucap dan bertingkah laku dalam kehidupan sehari-hari. Orang berkarakter berarti orang yang berkepribadian, berperilaku, bersifat, bertabiat, atau berwatak. Karakter identic dengan kepribadian atau akhlak. Kepribadian merupakan ciri, karakteristik, atau sifat khas diri seseorang yang bersumber dari bentukan-bentukan yang diterima dari lingkungan, misalnya keluarga pada masa kecil dan bawaan sejak lahir (Koesoema, 2007). Istilah karakter dihubungkan dan dipertukarkan dengan istilah etika, akhlak dan atau nilai-nilai dan berkaitan dengan kekuatan moral, berkonotasi “positif” bukan netral (Kemendiknas. 2011). 
JURNAL PENDIDIKAN ISLAM IQRA' Vol. 11. Nomor 1

Fakultas Tarbiyah dan Ilmu Keguruan [FTIK]

IAIN Manado

Proses pengembangan karakter pada seseorang dipengaruhi oleh banyak faktor oleh banyak faktor yang khas yang ada pada orang yang bersangkutan yang disebut faktor bawaan (nature) dan lingkungan (nature) di mana orang yang bersangkutan tumbuh dan berkembang. Faktor lingkungan dalam konteks pendidikan karakter memiliki peran yang sangat penting karena perubahan perilaku peserta didik sebagai hasil dari proses pendidikan karakter sangat ditentukan oleh faktor lingkungan. Pembentukan dan rekayasa lingkungan mencakup lingkungan fisik dan budaya sekolah, manajemen sekolah, kurikulum, pendidik dan metode mengajar. Pembentukan karakter melalui rekayasa lingkungan dapat dilakukan melalui strategi : 1) keteladanan, 2) intervensi, 3) pembiasaan yang dilakukan secara konsisten, dan 4) penguasaan (Kemendiknas, 2011)

Karakter bangsa bukan agregasi karakter perorangan, karena karakter bangsa harus terwujud dalam rasa kebanggaan yang kuat dalam konteks kultur yang beragam. Karakter bangsa mengandung perekat, kultural, yang harus terwujud dalam kesadaran kultural (cultural awareness) dan kecerdasan kultural (cultural intelligence) setiap warganegara (Kardinata, 2013).

Pusat kurikulum (2009) mengidentifikasi 18 nilai pendidikan karakter yang bersumber dari Agama, Pancasila, budaya dan tujuan pendidikan nasional, yaitu : (1) religius, (2) jujur, (3) toleransi, (4) disiplin, (5) kerja keras, (6) kreatif, (7) mandiri, (8) demokratis, (9) rasa ingin tahu, (10) semangat kebangsaan, (11) cinta tanah air, (12) menghargai prestasi (13) bersahabat/komunikatif, (14) cinta 
JURNAL PENDIDIKAN ISLAM IQRA' Vol. 11. Nomor 1

Fakultas Tarbiyah dan Ilmu Keguruan [FTIK]

IAIN Manado

damai, (15) gemar membaca, (16) peduli lingkungan, dan (17) peduli sosial dan (18) tanggungjawab.

Kedelapan belas nilai karakter tersebut dideskripsikan oleh sari (2013) dan Widiyanto (2013) sebagai berikut :

1. Religius, sikap dan perilaku yang patuh dalam melaksanakan ajaran agama yang dianutnya, toleran terhadap pelaksanaan ibadah agama lain dan hidup rukun dengan pemeluk agama lain

2. Jujur, perilaku yang didasarkan pada upaya menjadikan dirinya sebagai orang yang selalu dapat dipercaya dalam perkataan, tindakan dan pekerjaan

3. Toleransi sikap dan tindakan yang menghargai perbedaan agama, suku, etnis, pendapat, sikap dan tindakan orang lain, yang berbeda dengan dirinya

4. Disiplin, tindakan yang menunjukkan perilaku tertib dan patuh pada berbagai ketentuan dan peraturan

5. Kerja keras, perilaku yang menunjukkan upaya sungguh-sungguh dalam mengatasi berbagai belajar dan tugas serta menyelesaikan tugas dengan sebaik-baiknya.

6. Kreatif : berpikir dan melakukan sesuatu untuk menghasilkan cara atau hasil baru dari sesuatu yang telah dimiliki

7. Mandiri : sikap dan perilaku yang tidak mudah tergantung pada orang lain dalam menyelesaikan tugas-tugas

8. Demokratis : cara berpikir, bersikap dan bertindak yang menilai sama hak dan kewajiban dirinya dan orang lain 
JURNAL PENDIDIKAN ISLAM IQRA' Vol. 11. Nomor 1

Fakultas Tarbiyah dan Ilmu Keguruan [FTIK]

IAIN Manado

9. Rasa ingin tahu : sikap dan tindakan yang selalu berupaya untuk mengetahui lebih mendalam dan meluas dari sesuatu yang dipelajarinya, dilihat dan didengar

10. Semangat kebangsaan, cara berpikir, bertindak dan berwawasan yang menempatkan kepentingan bangsa dan Negara di atas kepentingan diri dan kelompoknya.

11. Cinta tanah air, cara berpikir dan berbuat yang menunjukkan kesetiaan, kepedulian dan penghargaan yang tinggi terhadap bahasa, lingkungan fisik, sosial, budaya, ekonomi dan politik bangsa

12. Menghargai prestasi, sikap dan tindakan yang mendorong dirinya untuk menghasilkan sesuatu yang berguna bagi masyarakat, dan mengakui serta menghormati keberhasilan orang lain.

13. Bersahabat/komunikatif tindakan yang memperlihatkan rasa senang berbicara, bergaul dan bekerjasama dengan orang lain

14. Cinta damai, sikap perkataan dan tindakan yang menyebabkan orang lain merasa senang dan aman atas kehadiran dirinya.

15. Gemar membaca, kebiasaan menyediakan waktu untuk membaca berbagai bacaan yang memberikan kebajikan bagi dirinya.

16. Peduli lingkungan, sikap dan tindakan yang selalu berupaya menengah kerusakan pada lingkungan akan disekitarnya dan mengembangkan upayaupaya untuk memperbaiki kerusakan alam yang sudah terjadi

17. Peduli sosial, sikap dan tindakan yang selalu ingin memberi bantuan pada orang lain dan masyarakat yang membutuhkan 
JURNAL PENDIDIKAN ISLAM IQRA' Vol. 11. Nomor 1

Fakultas Tarbiyah dan Ilmu Keguruan [FTIK]

IAIN Manado

18. Tanggungjawab, sikap dan perilaku seseorang untuk melaksanakan tugas dan kewajibannya, yang seharusnya dia lakukan, terhadap diri sendiri, masyarakat, lingkungan (alam, sosial dan budaya) Negara dan Tuhan Yang Maha Kuasa.

\section{Implementasi pendidikan karakter di sekolah dan perguruan tinggi}

Strategi pembangunan karakter bangsa melalui pendidikan dapat dilakukan dengan pendidikan, pembelajaran, dan fasilitasi. Dalam konteks makro, penyelenggaraan pendidikan karakter terhadap keseluruhan kegiatan perencanaan, pengorganisasian, pelaksanaan, dan pengendalian mutu yang melibatkan seluruh unit utama di lingkungan pemangku kepentingan pendidikan nasional. Peran pendidikan sangat strategis karena merupakan pembangun integrasi nasional yang kuat. Selain dipengaruhi faktor politik dan ekonomi, pendidikan juga dipengaruhi factor sosial budaya, khususnya dalam aspek integrasi dan ketahanan nasional (Pemerintah Republik Indonesia, 2011).

\section{a. Implementasi Pendidikan Karakter di Sekolah}

Pendidikan karakter dapat berkembang dengan baik melalui budaya sekolah yang mendukung. Pembentukan budaya sekolah (school culture) dapat dilakukan melalui rangkaian kegiatan : perencanaan, pelaksanaan pembelajaran yang lebih berorientasi pada peserta didik, dan penilaian yang bersifat komprensif. Perencanaan di tingkat sekolah, seperti menetapkan visi, misi, tujuan, struktur kurikulum, kalender akademik, penyusunan silabus, dan rencana pelaksanaan pembelajaran (RPP). Keseluruhan perencanaan sekolah yang bertitik tolak dari melakukan analisis kekuatan dan kebutuhan sekolah 
JURNAL PENDIDIKAN ISLAM IQRA' Vol. 11. Nomor 1

Fakultas Tarbiyah dan Ilmu Keguruan [FTIK]

IAIN Manado

akan dapat dihasilkan program pendidikan yang lebih terarah yang tidak semata-mata berupa penguatan ranah pengetahuan dan keterampilan melainkan juga sikap perilaku uang akhirnya dapat membentuk akhlak budi luhur. Pendidikan karakter bukan merupakan mata pelajaran atau nilai yang diajarkan, tetapi lebih pada upaya penanaman nilai-nilai, baik melalui semua mata pelajaran, program pengembangan diri, dan budaya sekolah (Kementerian Pendidikan Nasional, 2011).

Strategi, pelaksanaan pendidikan karakter di satuan pendidikan karakter di satuan pendidikan merupakan suatu kesatuan dari program manajemen peningkatan mutu berbasis sekolah yang terimplementasi dalam pengembangan, pelaksanaan, dan evaluasi oleh satuan pendidikan. Pendidikan karakter dalam satuan pendidikan dapat diimplementasikan secara optimal melalui langkah-langkah sebagai berikut ini :

Tabel 2 Implementasi Pendidikan Karakter Dalam Satuan Pendidikan

\begin{tabular}{|c|c|}
\hline \multicolumn{2}{|c|}{ Implementasi Pendidikan Karakter Dalam Satuan Pendidikan } \\
\hline 1. Integrasi dalam mata pelajaran & $\begin{array}{l}\text { Membangun silabus dan RPP pada } \\
\text { kompetensi yang telah ada sesuai } \\
\text { dengan nilai yang akan diterapkan }\end{array}$ \\
\hline 2. Integrasi dalam muatan lokal & $\begin{array}{l}\text { - Diterapkan oleh satuan pendidikan } \\
\text { - Kompetensi dikembangkan oleh } \\
\text { satuan pendidikan }\end{array}$ \\
\hline 3. Kegiatan pengembangan diri & $\begin{array}{ll}- & \text { Pembudayaan dan pembiayaan } \\
\checkmark & \text { Pengkondisian } \\
\checkmark & \text { Kegiatan rutin } \\
\checkmark & \text { Kegiatan spontanitas } \\
\checkmark & \text { Keteladanan }\end{array}$ \\
\hline
\end{tabular}




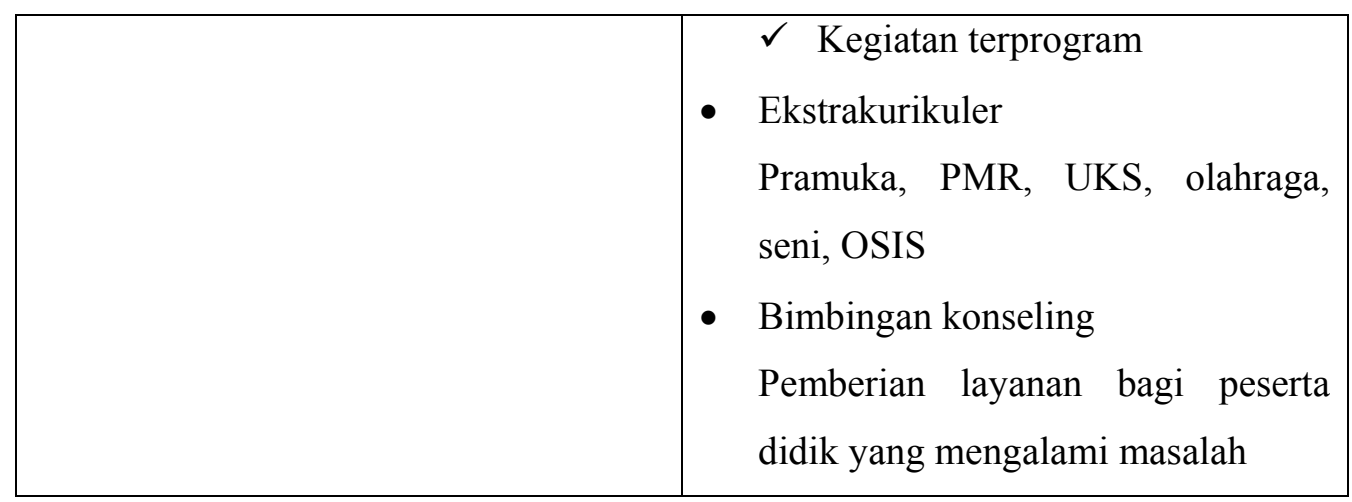

(Sumber Kementerian Pendidikan Nasional, 2011)

Kegiatan pembelajaran dalam kerangka pengembangan karakter peserta didik dapat menggunakan pendekatan pembelajaran aktif seperti pendekatan belajar kontekstual, pembelajaran kooperatif, pembelajaran berbasis masalah, pembelajaran berbasis proyek, pembelajaran berbasis kerja dan ICARE (Introduction, Conection, Application, Reflection, Extension), dapat digunakan untuk pendidikan karakter (Kementerian Pendidikan Nasional, 2011).

Berdasarkan uraian tersebut, logikanya dapat dibalik bahwa pembelajaran aktif dapat dimanfaatkan untuk pengembangan pendidikan karakter di sekolah. Dengan memilih pendekatan pembelajaran aktif, guru melakukan pembiasaan kepada siswa melalui pengenalan nilai-nilai, dan sampai pada taraf tertentu menjadikan peserta didik peduli dan mengimplementasi nilai-nilai. Integritas pendidikan karakter pada mata pelajaran tertentu mengarah pada internalisasi nilai-nilai dalam tingkah laku sehari-hari melalui proses pembelajaran dari tahapan perencanaan, pelaksanaan, dan penilaian.

Pengembangan nilai-nilai karakter di setiap mata pelajaran dapat dilakukan dengan mengintegrasikan nilai-nilai pendidikan karakter ke dalam Kompetensi Inti (KI) dan Kompetensi Dasar (KD) sesuai dengan kurikulum 2013 (K13) 
JURNAL PENDIDIKAN ISLAM IQRA' Vol. 11. Nomor 1

Fakultas Tarbiyah dan Ilmu Keguruan [FTIK]

IAIN Manado

jumlah KD di setiap mata pelajaran yang dapat diintegrasikan nilai-nilai pendidikan karakter tentu berbeda. Selanjutnya kompetensi dasar yang dapat diintegrasikan nilai-nilai pendidikan karakter tersebut dikembangkan pada silabus dan rencana pelaksanaan pembelajaran (RPP), dan diimplementasikan dalam pelaksanaan pembelajaran secara nyata (real).

\section{b. Implementasi Pendidikan Karakter di Perguruan Tinggi}

Pelaksanaan pendidikan karakter di perguruan tinggi dapat diintegrasikan ke dalam kegiatan tridarma perguruan tinggi, yaitu pendidikan dan pengajaran, penelitian dan pengabdian kepada masyarakat yang berkarakter (Dharmawan, 2014). Pengintegrasian pendidikan karakter ke dalam perkuliahan memerlukan perencanaan yang terpadu. Implementasi pendidikan karakter beserta monitoring dan evaluasinya pun harus sudah disiapkan dengan baik. Pendidikan karakter tidak cukup dengan cara langsung yang memiliki ciri intelektual, karena nilainilainya hanya akan diserap/dihafalkan tetapi tidak terinternalisasi apalagi diramalkan (Winarni, 2013).

Selanjutnya Winarni (2013) menyatakan pengintegrasian pendidikan karakter dalam perkuliahan memerlukan model pembelajaran untuk mengkonstruk penanaman nilai atau karakter yang diharapkan. Beberapa contoh model pembelajaran terpadu yaitu : pembelajaran terpadu model terhubung (connected), pembelajaran terpadu model tematik (Webbed), pembelajaran terpadu model antar bidang studi (Integrated), pembelajaran terpadu model tersarang (Nested). Model terhubung (connected) merupakan model integrasi interbidang studi. Model ini 
JURNAL PENDIDIKAN ISLAM IQRA' Vol. 11. Nomor 1

Fakultas Tarbiyah dan Ilmu Keguruan [FTIK]

IAIN Manado

secara nyata mengintegrasikan satu konsep keterampilan atau kemampuan yang ditumbuhkembangkan dalam satu pokok bahasan atau subpokok bahasan dalam satu bidang studi. Kaitan dapat diadakan secara spontan atau direncanakan terlebih dahulu. Pembelajaran terpadu model webbed adalah pembelajaran terpadu yang menggunakan model tematik. Pengembangan dimulai dengan menentukan tema tertentu. Tema bisa diterapkan dengan negosiasi antar guru dan siswa, tetapi dapat pula dengan cara diskusi sesama guru. Setelah tema disepakati, dikembangkan sub-sub tema dikembangkan aktivitas belajar yang harus dilakukan siswa. Pembelajaran terpadu model integrated menggunakan pendekatan antar bidang studi, menggabungkan bidang studi dengan cara menetapkan prioritas kurikuler dan menemukan konsep, keterampilan, dan sikap yang saling tumpang tindih. Model pembelajaran terpadu tersarang (nested) merupakan pengintegrasian kurikulum dalam satu disiplin ilmu, fokus pengintegrasian meliputi keterampilan berpikir, keterampilan sosial dan keterampilan mengorganisir. Karakteristik mutu pelajaran menjadi pijakan untuk menentukan keterampilan belajar.

Fogarty (1991:28) menyatakan untuk mata pelajaran sosial dan bahasa dapat dipadukan keterampilan berpikir dengan keterampilan sosial, sedangkan mata pelajaran matematika dan sains dapat dipadukan keterampilan berpikir dan keterampilan mengorganisir. Winarni (2013) menyatakan dengan memperhatikan pengintegrasian pendidikan karakter dalam perkuliahan dapat dipahami bahwa model tersarang (mested) cukup leluasa membantu pengorganisasian materi dan keterampilan lain seperti keterampilan yang berkaitan dengan berperilaku (soft skill) karakter atau nilai-nilai moral yang diintegrasikan dengan mata kuliah. 
JURNAL PENDIDIKAN ISLAM IQRA' Vol. 11. Nomor 1

Fakultas Tarbiyah dan Ilmu Keguruan [FTIK]

IAIN Manado

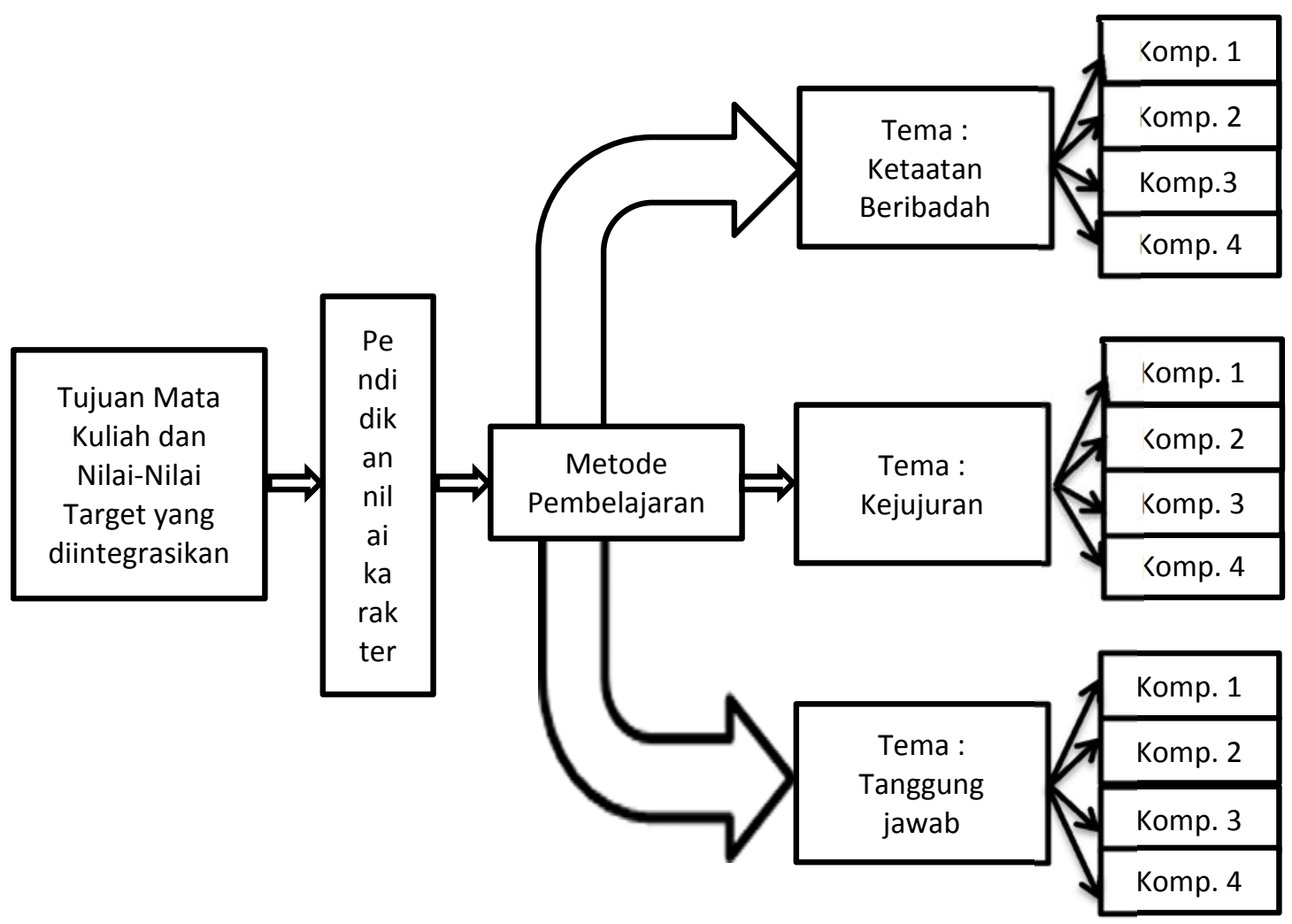

Pelaksanaan pendidikan karakter integrasi dalam proses pembelajaran meliputi proses penyusunan silabus, penyusunan RPP, penyiapan, serta tindak lanjut (Winarni, 2013), pembiasaan dalam kehidupan keseharian di perguruan tinggi dapat terintegrasi ke dalam budaya perguruan tinggi (kampus) atau budaya organisasi, implementasi pendidikan karakter bangsa dapat diintegrasikan ke dalam kegiatan kemahasiswaan dalam bentuk aktivitas kekurikuler dan/atau ekstrakurikuler, seperti pramuka, olahraga, karya tulis, seni dan lain-lain. Selain itu penerapan pembiasaan kehidupan keseharian dalam rangka pendidikan karakter bangsa dapat disisipkan dalam setiap interaksi di lingkungan keluarga, asrama dan masyarakat. Perspektif nilai-nilai karakter dalam totalitas budaya 
JURNAL PENDIDIKAN ISLAM IQRA' Vol. 11. Nomor 1

Fakultas Tarbiyah dan Ilmu Keguruan [FTIK]

IAIN Manado

akademik pada gilirannya akan membentuk budaya akademik yang berkualitas (Dharmawan, 2014).

Selanjutnya, Dharmawan (2014) menyatakan program pengembangan mahasiswa pada dasarnya merupakan kegiatan ekstrakurikuler sebagai penunjang kurikuler yang dirancang sedemikian rupa agar menjadi program yang terintegrasi. Pendekatan yang digunakan adalah berproses, terpadu dan berkelanjutan. Ranah pembinaan kegiatan kemahasiswaan di perguruan tinggi biasanya terbagi ke dalam pembinaan : 1) penalaran, keilmuan, dan keprofesian, 2) minat, bakat, dan kegemaran, 3) organisasi mahasiswa, 4) sosial kemasyarakatan. Masing-masing ranah memiliki tujuan seperti : menanamkan sikap ilmiah dan profesionalisme, mengaktualisasikan minat dan kegemaran serta bakat untuk menunjang perkembangan jasmani dan rohani, mengembangkan organisasi kemahasiswaan di lingkungan perguruan tinggi, mengaktualisasikan hasrat dan kepekaan sosial untuk berinteraksi dengan masyarakat.

\section{Simpulan}

Pengembangan pendidikan karakter di sekolah dapat melalui jalur kekurikuler (pembelajaran semua mata pelajaran) dan ekstrakurikuler (OSIS, pramuka, seni dan olahraga), di perguruan tinggi dapat melalui jalur tridarma (pendidikan dan pengajaran, penelitian dan pengabdian kepada masyarakat). Pendidikan karakter dapat dikembangkan melalui budaya sekolah (school culture) melalui serangkaian kegiatan : perencanaan, pelaksanaan pembelajaran yang lebih berorientasi pada peserta didik, dan penilaian yang bersifat komprehensif. Di 
JURNAL PENDIDIKAN ISLAM IQRA' Vol. 11. Nomor 1

Fakultas Tarbiyah dan Ilmu Keguruan [FTIK]

IAIN Manado

pihak lain, pendidikan karakter bangsa perlu dibudayakan di perguruan tinggi, melalui budaya organisasi, kegiatan kemahasiswaan, dan kegiatan keseharian.

Implementasi pendidikan karakter dalam proses belajar mengajar di kelas harus terintegrasi dengan semua mata pelajaran, dipihak lain di perguruan tinggi harus terintegrasi dengan semua mata kuliah yang diprogram untuk mahasiswa. Pendidikan karakter tidak sebagai mata pelajaran atau mata kuliah yang berdiri sendiri. Dalam pelaksanaan proses belajar mengajar, guru dapat menggunakan pendekatan pembelajaran aktif seperti pendekatan belajar kontekstual, pembelajaran kooperatif, pembelajaran berbasis masalah, pembelajaran berbasis proyek, pembelajaran pelayanan, pembelajaran berbasis kerja dan ICARE (introduction, connection, Application, Reflection, Extension) dapat digunakan dalam pendidikan karakter. Sedangkan di perguruan tinggi, model pembelajaran tersarang (nested) dapat membantu pengorganisasian materi dan keterampilan belajar mahasiswa.

Daftar Pustaka

Bransford, J.D, Shorwood, R.D. Hasselbring, T.S. Kinzer, C.K. and Williams, S.M. 1990. Anchored instruction: why we need it and how technology can help in Nix. D. And Spiro R. (eds), Cognition, Education and multimedia: exploring ideas in High Technology (PP. 115-41), Hilisdale NJ, Lawrence Erlbaum.

Chikering, A. w. and Gamson, Z.F, Seven Principles for good practice in undergraduate education. AAHE Bulletin 39:3-7. ED 282 491. 6 PP, 1987.

Dharmawan, Nyoman Sadra. 2014. Implementasi Pendidikan Karakter Bangsa Pada Mahasiswa di Perguruan Tinggi, Makalah Pembinaan Pendidikan Karakter bagi Mahasiswa PTS di lingkungan Kopertis Wilayah III Tahun 2014. 
JURNAL PENDIDIKAN ISLAM IQRA' Vol. 11. Nomor 1

Fakultas Tarbiyah dan Ilmu Keguruan [FTIK]

IAIN Manado

Djalil, Sofyan, dan Rata Megawangi. Peningkatan Mutu Pendidikan di Aceh Melalui Implementasi Model Pendidikan Holistik Berbasis Karakter. Orasi ilmiah dalam rangka Dies Natalis ke-45 Universitas Syiah Kuala 2 September 2006.

Fogarty, R. 1991. The Mindful School: How to integrate the Curicula. Palatine, 1llonois: IRI/Skylight Publishing. Inc.

Gardner, H. 1993. Multiple Intellegences: the theory in practice. New York: Basic Books.

Kementerian Pendidikan Nasional. 2011. Desain Induk Pendidikan Karakter. Kementerian Pendidikan Nasional. Jakarta.

Lickona, T. 1992. Educating for Character; Hoe our School can Teach Respect and Responsibility. New York. Batam Books

Marzuki. 2012. Grand Desain Pendidikan Karakter dan Pengembangan Kultur di UNY. Makalah Workshop re desain Pendidikan Karakter UNY, 5 September 2012

Overbauh, R.C. and Schultz, L. Bloom's Taxonomy. www.edu/educ/roverbau/Bloom/blooms.taxonomy.htm. Download 7 March 2016

Paulson, D.R. and Faust, J.L. Active Learning for the college classroom. http//www.calstatela.edu.dept/chem/chem2/active/index.htm. download 7 March 2016

Prince, M. Does Active Learning Work? A Review of Literature Journal of engineering education 93 (3). 2004.

Pusat Kurikulum. 2009. Pengembangan dan pendidikan Budaya dan Karakter Bangsa. Pedoman Sekolah. Jakarta.

Sukarno, 2012. Active Learning for Higher Education. Unfolding the Theoretical Issues and Practice. Transformatika. Edisi Februari 2014

Trianto, 2007. Model Pembelajaran Terpadu dalam Teori dan Praktik. Jakarta: Prestasi Pustaka.

Tim DBE, 2010. Active Learning for Higher Education (ALFHE) USAIDIndonesia 
JURNAL PENDIDIKAN ISLAM IQRA' Vol. 11. Nomor 1

Fakultas Tarbiyah dan Ilmu Keguruan [FTIK]

IAIN Manado

Winarni, Sri. 2013. Integrasi Pendidikan Karakter dalam Perkuliahan. Dalam Jurnal Pendidikan Karakter. Th. III. No. 1, Februari 2013. Hal. 95-107. 